\title{
Systemic Lupus Erythematosus Disease Activity Index
}

National Cancer Institute

\section{Source}

National Cancer Institute. Systemic Lupus Erythematosus Disease Activity Index. NCI

Thesaurus. Code C97984.

A clinical index for the measurement of disease activity in systemic lupus erythematosus.

The index utilizes 24 weighted variables that measure disease activity, damage from disease, and health status. 